\section{Aptitudes of the Bantu}

THE aptitude of the Bantu when brought into contact with new ideas is sometimes almost startling. One cannot foresee whether he is likely to display remarkable aptitude or stark incapacity. A question, for example, that psychologists might investigate is why the average African native can quickly learn to handle a complicated agricultural tractor or compressed air drill, while the most sophisticated of them seem quite incapable of running a small country store (or general shop) on their own account.

Ten quite ordinary natives in Salisbury, Southern Rhodesia, were induced, as an experiment, to attend classes in Red Cross work and recently sat for their examinations, as first-year candidates. There were five subjects : (1) hæmorrhage control ; (2) slings or dressings ; (3) fractures; (4) drowning or asphyxia; and (5) transport.

For (1) hæmorrhage control, one got full marks and the average was 76 per cent. For (2) slings and dressings, every candidate's average was 80 per cent. For (3) fractures, two got full marks and the average was 80 per cent. For (4) drowning, and asphyxia, two got full marks and the average was 83 per cent. For (5) transport, six got full marks, three 90 per cent and one 80 per cent.

For the whole examination the best man scored 94 per cent and the lowest 80 per cent.

Judged by any standards, this is a remarkably fine performance and, by the way, also reflects great credit on the Rhodesian Red Cross authorities.

41 Talbot Road,

F. M. C. Stokes.

Highgate, N.6.

Nov. 23.

\section{Some New Phenomena produced by Sound Vibrations}

\section{Acoustic jets and liquid diaphragms.}

UsING as a source of sound the singing tube recently shown by me to the Physical Society ${ }^{1}$, I have obtained some effects at the interface between a shallow layer of liquid and the gas above it, which do not appear to have been previously described ${ }^{2}$.

A glass tube, two or more feet in length, about one inch in diameter, and open at both ends, is slightly curved in a vertical plane so that it may hold a shallow layer of water, oil, or other liquid. When one end of this tube is brought sufficiently close to an open end of the singing tube, one or more liquid diaphragms may suddenly be formed right across the tube. The positions and behaviour of these liquid diaphragms vary with their thickness. Diaphragms five or more millimetres thick are covered with a ripple pattern and appear to be still. Thinner diaphragms erupt a stream of liquid or droplets from both surfaces, while still thinner diaphragms disintegrate in an explosive manner soon after their formation. The formation and breakdown of the liquid diaphragms is often accompanied by 'tides' in the liquid simulating the seiches observed on lakes. The addition of powdered mica to the liquid permits the formation of a semi-permanent membrane across the tube which persists after the sound is cut off.

\section{A sonic amplifier and pendulum maintained by sound vibrations.}

A short length of glass tubing, closed at one end by a stretched thin rubber diaphragm, when slipped over the end of a sounding Knipp's tube ${ }^{3}$, re-enforces its note for a relatively wide range of positions. A position can be found in which a slight touch on the diaphragm stops the sound. If the bob of a bifilar pendulum be allowed to impinge on the diaphragm when it is in this sensitive position, the vibrations of the pendulum may be maintained and the noise of the impacts exalted to the tappings of a drum.

A frequency demultiplication factor exceeding one hundred may easily be obtained with the system.

Medical College,

F. L. HOPWOOD.

St. Bartholomew's Hospital, E.C.I. Dec. 8.

1 Meeting of Phys. Soc., Oct. 23, 1936.

2 Robinson and Stephens, Phil. Mag., Ser. 7, 17, 27, have studied the effects of sound waves on soap flims.

${ }^{3}$ C. T. Knipp, Phys. Rev., Dec. 1918.

\section{Adjustable Resonators and Orchestration}

THE description of the Hammond organ by Sir James Barrett in NATuRE of August 15 (p. 297) prompts the physiologist to ask why orchestration does not yet employ the method of the adjustable resonator so important in human speech and song. A very slight alteration in the calibre of the supralaryngeal passages will make a profound difference in the quality of the voice, as every singer knows. In a few instruments of minor importance there can be found a series of resonators, but these are incapable of change. A good violin player can, by alteration of pressure and of bowing, make some adjustments in the resonance, but the range of such is small com. pared with the human voice.

One can picture the orchestra of the future placed on a huge resonator with electrically worked pistons, bulkheads and dampers. The conductor, it is true, would have one more score to direct with eye and baton. When on this topic, may I ask if experiments have been made to construct acoustic membranes for reception or emission on the principle of the mammalian ear-drum ?

\section{University of Melbourne.}

\section{W. A. Osborne.}

$$
\text { Oct. } 12 \text {. }
$$

\section{Directions of Homogeneous Auroral Arcs}

The Oxford University Arctic Expedition 1935-36 wintered in North-east Land at $80^{\circ} 23^{\prime} \mathrm{N} ., 19^{\circ} 3 \mathrm{I}^{\prime} \mathrm{E}$., where single photographs of the homogeneous auroral arcs were taken in order to determine their direction. The photographs were reduced by the method used by Wesöe ${ }^{1}$ and Störmer ${ }^{2}$. Persistent cloudiness prevented many photographs being made, but the average of fourteen measurements was $73^{\circ} \mathrm{E}$. of $\mathrm{N}$. for the region $80^{\circ} \mathrm{N}$. to $76^{\circ} \mathrm{N}$, $15^{\circ} \mathrm{E}$. to $40^{\circ} \mathrm{E}$. The individual determinations were $84^{\circ}, 78^{\circ}, 65^{\circ}, 68^{\circ}, 91^{\circ}$, $65^{\circ}, 66^{\circ}, 70^{\circ}, 73^{\circ}, 67^{\circ}, 70^{\circ}, 95^{\circ}, 85^{\circ}, 48^{\circ}$ E. of $\mathrm{N}$.

I wish to express my thanks to Dr. Harang, who reduced the photographs at the Auroral Observatory, Tromsö, and gave us much assistance.

Merton College,

R. A. Hamilton.

Oxford.

Nov. 27.

1 The Norwegian North Polar Expedition with the Maud, 19181925. Scientific Results, 1, No. 6 (Bergen, 1928).

${ }^{2}$ Geof. Publ., 4, No. 7 (Oslo, 1926). 